\title{
Another ounce of prevention - Immunization of human immunodeficiency virus-infected adults
}

$\mathrm{T}$ HE ADVENT OF HUMAN IMMUNODEFICIENCY VIRUS (HIV) infection and its attendant problems has focused new attention on the importance of preventive strategies in individuals with compromised host defenses. Advances in the treatment and prophylaxis of opportunistic infections associated with acquired immune deficiency syndrome (AIDS), and indeed treatment of the underlying retroviral infection itself, have given additional years of productive life to these patients. Their quality of life may be enhanced further by the appropriate use of immunization directed towards vaccinepreventable diseases.

The immunosuppression resulting from HIV infection is complex and includes defects in both cellmediated and humoral immunity (1-3). Vaccine responsiveness and efficacy relate to the individual's net state of immunosuppression at administration; this point must be taken into account when considering strategies of immunization for the HIV-infected person. An effort should be made to immunize individuals as early as possible to maximize the likelihood of a good response.

Currently recommended immunizations for HIV-infected adults include tetanus-diphtheria (Td) toxoid, influenza vaccine and pneumococcal vaccine. Haemophilus influenzae type b conjugate vaccine (HbCV) may be considered for HIV-infected adults and hepatitis B, combined measles, mumps, rubella (MMR) and inactivated poliomyelitis (IPV) vaccines should also be given if indicated $(4,5)$.

As for all adults, a booster dose of Td should be given every 10 years to those who have received a primary series $(4,5)$ to ensure maintenance of immunity to tetanus and diphtheria.

Although there are no studies to demonstrate an increased risk of death secondary to influenza in HIV infected adults, there may be a trend towards a pro longed duration of illness and more respiratory compromise (6); annual influenza vaccination of these individuals is recommended. Recent studies have demonstrated protective antibody levels may be at tained in 50 to $90 \%$ of asymptomatic HIV-infected indi viduals $(7,8)$. There are discrepancies, however, in the level of protective antibody response attained in persons with AIDS $(7,8)$. An increased incidence of infection secondary to Streptococcus pneumoniae has been clear ly documented in patients with AIDS and, thus, pneu mococcal vaccine is recommended for HIV-infected in dividuals $(9,10)$. Studies of pneumococcal vaccine response suggest there may be a reduced antibody response in HIV-infected persons compared with con trols, but the level may still be protective (7).

Because persons with HIV infection are at increased risk of serious infections with $H$ influenzae type $b$ and immunization with $\mathrm{HbCV}$ early in the course of HIV infection likely confers protection against invasive dis ease (11), HbCV may be considered for HIV-infected persons. The efficacy of immunization with $\mathrm{HbCV}$ in this population is unknown.

Although live virus vaccines generally should not be given to immunosuppressed persons, measles may cause progressive fatal disease in susceptible HIV-in fected individuals (12); thus, MMR should be given to adults with HIV infection who have no history of meas 
les and did not previously receive the measles vaccine, High risk behaviour in certain risk groups for HIV infection increases the risk of acquiring hepatitis $B$ infection, and although attempts to reduce risk-taking behaviour should be emphasized, the use of active immunization in this population is recommended. Recent evidence suggests that HIV-infected persons who are hepatitis B antibody-negative may be at increased risk of chronic HBV infection (13).

Although oral polio vaccine (OPV) has not been harmful when given to HIV-infected persons, it should not be used; rather, IPV (if indicated) is preferred since it eliminates any theoretical risk to the vaccine and prevents the possibility of vaccine virus spread to any immunosuppressed close contacts.

Although childhood immunization has substantially reduced the occurrence of many vaccine-preventable diseases and is considered routine in pediatric populations, such success has not been achieved in adult populations where vaccines are generally underused. In the HIV-infected adult, the prudent use of immunization to prevent the unnecessary occurrence of vaccinepreventable diseases cannot be overemphasized. With the use of a systematic and conscious approach to vaccination in this population, a significant reduction in the morbidity and mortality of these vaccine-preventable diseases may be achieved.

\section{REFERENCES}

1. Lane HC, Fauci AS. Immunologic abnormalities in the acquired immunodeficiency syndrome. Ann Rev Immunol 1985;3:477-500.

2. Ammann AJ, Schiffman G, Abrams D, Volberding P Ziegler J, Conant M. B cell immunodeficiency in the acquired immune deficiency syndrome. JAMA 1984;251:1447-9.
3. Rosenberg Z, Fauci A.. Immunopathogenesis of HIV infection. FASEB J 1991;5:2382-90.

4. ACIP: Recommendations of the Immunization Practices Advisory Committee. Update on adult immunization. MMWR 1991;40:12-15,59.

5. National Advisory Committee on Immunization. Canadian Immunization Guide, 3rd edn. Ottawa: Department of National Health and Welfare, 1989:17-18, 28-30.

6. Safrin S, Rush JD, Mills J. Influenza in patients with human immunodeficiency virus infection. Chest 1990;98:33-7.

7. Huang K-L, Rubed PL, Rinaldo CM Jr, Kingsley L, Lytes DW, Ho M. Antibody responses after influenza and pneumococcal immunization in HIV-infected men. JAMA 1987;257:2047-50.

8. Nelson KE, Clements ML, Miorti P, Cohn S, Polk BF. The influence of human immunodeficiency virus infection on antibody responses to influenza vaccine. Ann Intern Med 1988; 109:383-8.

9. Polsky B, Gold JWM, Whimbey E, et al. Bacterial pneumonia in patients with acquired immunodeficiency syndrome. Ann Intern Med 1986;104:38-41.

10. Simberkoff MS, El Sadr W, Schiffman G Jr, Rhal J. Streptococcus pneumoniae infections and bacteremia in patients with acquired immune deficiency syndrome with report of pneumococcal vaccine failure. Am Rev Respir Dis $1984 ; 130$ : 1174-6.

11. Steinhoff M, Averbach B, Nelson K, et al. Antibody responses to Haemophilus influenzae type $B$ vaccines in men with human immunodeficiency virus infection. N Engl J Med 1991;325:1837-42.

12. ACP Task Force on Adult Immunization and Infectious Disease Society of America. Guide for Adult Immunization, 2nd edn. Philadelphia: American College of Physicians, 1990:43-9.

13. Hadler SC, Judson F, Echenberg D, et al. Effect of prior human immunodeficiency virus on outcome of hepatitis B virus infection. J Med Virol 1987;21:87A.

JM Conly, MD, FRCPC Saskatchewan, Saskatoon S Shafran, MD, FRCPC Edmonton, Alberta 


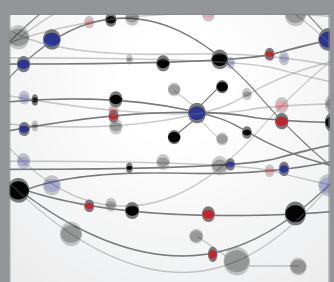

The Scientific World Journal
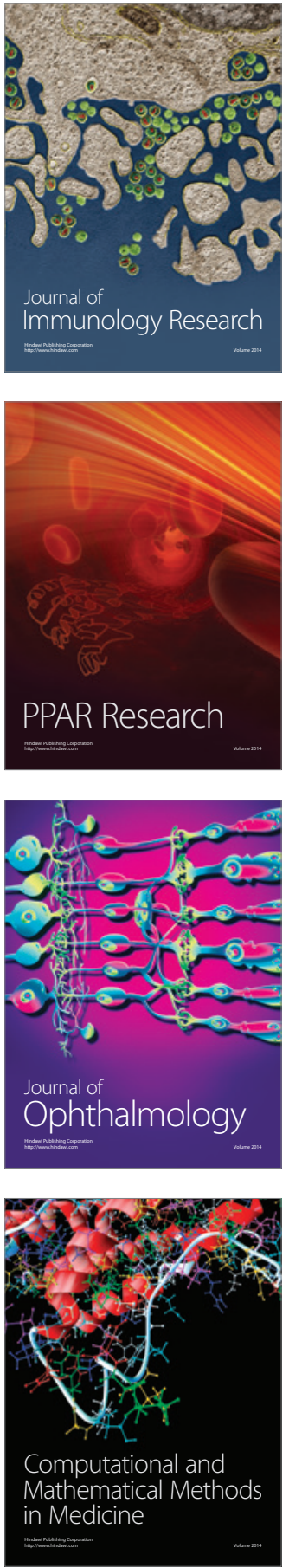

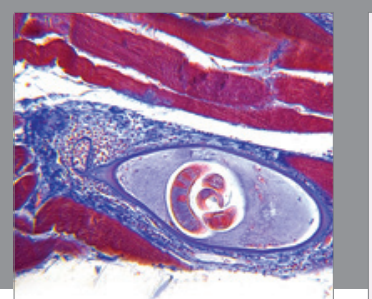

Gastroenterology Research and Practice

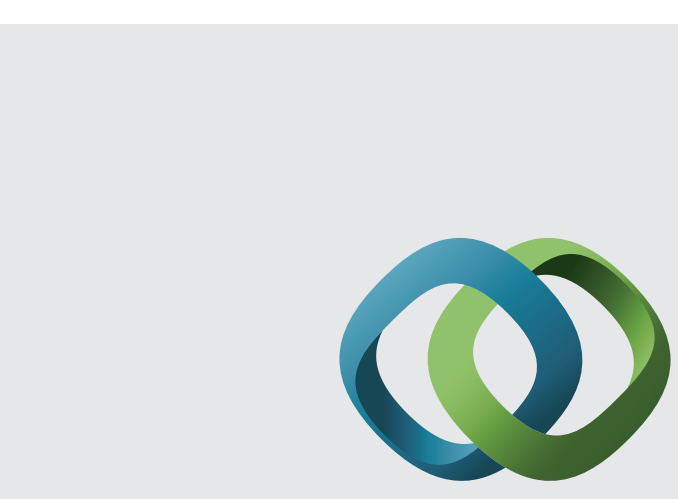

\section{Hindawi}

Submit your manuscripts at

http://www.hindawi.com
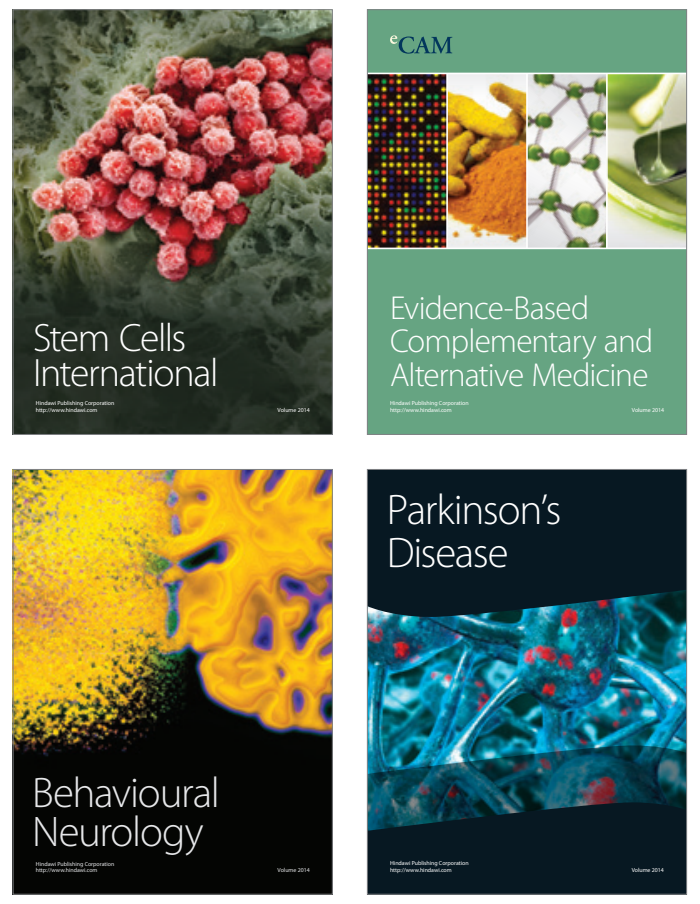
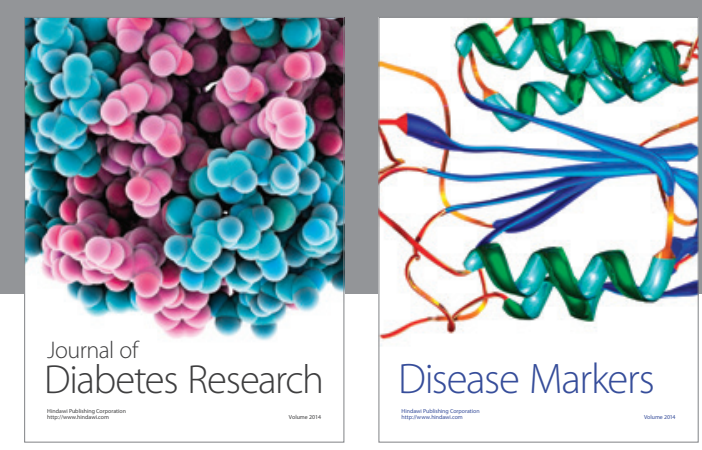

Disease Markers
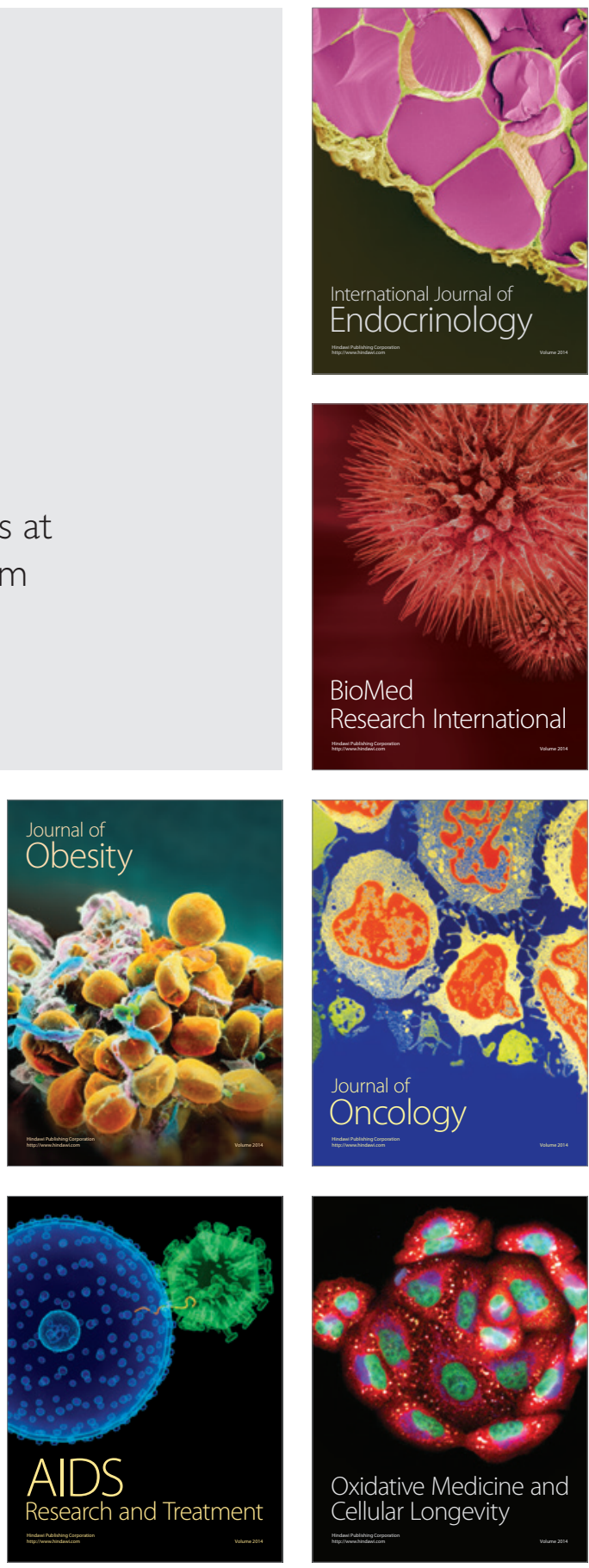